\title{
Determinación de la competitividad de destino turístico. Aplicación en Holguín para el mercado Estadounidense.
}

\section{Determination of the competitiveness of tourist destination. Application in Holguin for the US market.}

\begin{abstract}
MSc. Justa Medina Labrada., ${ }^{1}$ Lic. Elizabeth del Carmen Pérez Ricardo., ${ }^{2}$ \& Lic. Milagros Riquenes Gainza. ${ }^{3}$
\end{abstract}

\section{Resumen.}

El restablecimiento de las relaciones diplomáticas entre Cuba y Estados Unidos en 2015 provocó un crecimiento importante, a partir de ese año, del flujo de visitantes estadounidenses a Cuba. A pesar de las restricciones legales que en la actualidad desestimulan dichos flujos, se consideró conveniente evaluar la atractividad competitividad del destino turístico Holguín para distintos segmentos de clientes estadounidense, con el propósito de favorecer la elección o ampliación de los negocios turísticos con mayores posibilidades de éxito en este destino, una vez que se flexibilicen las restricciones a los estadounidenses para viajar a la Isla, considerando además que el turismo en Cuba es un sector estratégico, entre cuyos objetivos está el fortalecimiento de la competitividad. Para desarrollar el estudio se propuso un procedimiento, que considera las mejores experiencias precedentes y que combina el análisis de la atractividad y la competitividad, el cual es menos complejo y favorece la obtención de la información necesaria. Como resultado de la aplicación del procedimiento se determinaron los aspectos favorables y desfavorables que presenta el destino Holguín con relación a la atractividad turística para cada segmento; así como la posición competitiva que ocupa Holguín dentro de los destinos cubanos para los segmentos de yatistas y cruceristas y en comparación con otros destinos del Caribe para los que acceden por vía aérea. Se realizaron recomendaciones, para cada segmento, en función de favorecer la gestión efectiva del destino Holguín para dicho mercado.

Palabras claves: atractividad, competitividad, destino turístico, segmentos de mercado estadounidenses.

\footnotetext{
${ }^{1}$ Universidad de Holguín. Cuba. elizabeth.ricardo@uho.edu.cu

${ }^{2}$ Hotel Brisas Guardalavaca. Cuba.noelfc93@ nauta.cu

${ }^{3}$ Universidad de Holguín. Cuba.jmedina@uho.edu.cu
} 


\begin{abstract}
.
The restoration of diplomatic relations between Cuba and the United States in 2015 caused a significant growth, starting in that year, of the flow of American visitors to Cuba. Despite the legal restrictions currently discouraging such flows, it was considered appropriate to evaluate the attractiveness - competitiveness of Holguín tourist destination for different segments of US customers, with the purpose of favoring the choice or expansion of tourism businesses with greater possibilities of success in this destination, once the restrictions on Americans to travel to the island are relaxed, considering also that tourism in Cuba is a strategic sector, among whose objectives is the strengthening of competitiveness. To develop the study, a procedure was proposed, which considers the best previous experiences and combines the analysis of attractiveness and competitiveness, which is less complex and favors obtaining the necessary information. As a result of the application of the procedure, the favorable and unfavorable aspects of the Holguín destination were determined in relation to the tourism attractiveness for each segment; as well as the competitive position occupied by Holguin within Cuban destinations for the segments of yachtsmen and cruise passengers and in comparison with other destinations in the Caribbean for those who access by air. Recommendations were made for each segment, in order to favor the effective management of the Holguín destination for said market.
\end{abstract}

Keywords: attractiveness, competitiveness, tourist destination, US market segments.

\title{
Introducción
}

Durante las seis últimas décadas, el turismo ha experimentado una continua expansión y diversificación, convirtiéndose en uno de los sectores económicos de mayor envergadura y crecimiento del mundo. Un número creciente de destinos se han abierto al turismo y han invertido en él, haciendo del mismo un sector clave para el progreso socioeconómico, a través de la creación de puestos de trabajo y de empresas, la generación de ingresos de exportación y la ejecución de infraestructuras, de acuerdo a la OMT (2015).

Con el comienzo del restablecimiento de las relaciones diplomáticas entre Cuba y los Estados Unidos, el 17 de diciembre de 2015, se abrieron nuevas perspectivas para el arribo de flujos turísticos provenientes de Estados Unidos a Cuba. Esta decisión, unido a las medidas que flexibilizaron los viajes de estadounidenses a Cuba propiciaron el aumento del arribo de estadounidenses por vía aérea y marítima, como se muestra en la siguiente figura. 
Figura 1. Arribo de estadounidenses a Cuba 2014-2017 (No incluye cubanoamericanos)

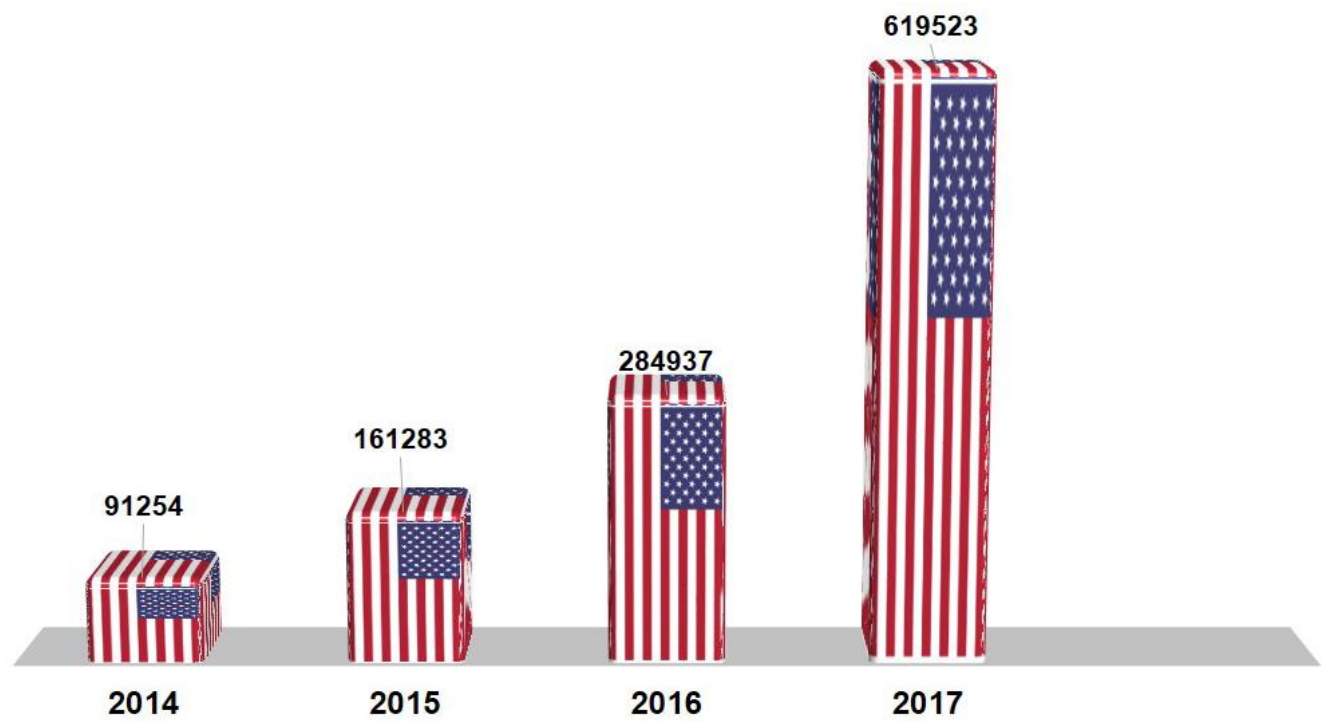

Fuente: elaboración propia basado en datos de la ONEI.

El mayor volumen de arribos se produce por vía aérea, favorecido por el establecimiento de numerosos vuelos regulares a varios destinos cubanos, entre ellos Holguín, que también ha experimentado un aumento del arribo de estadounidenses.

En relación con los segmentos de clientes que arriban por vía marítima: yatistas y cruceristas, Cuba se ubica geográficamente en El Caribe, una de las regiones principales a nivel mundial para el desarrollo de la actividad náutica. La modalidad de yatismo está en expansión y el segmento de yatistas estadounidense es el mayor a nivel mundial, con una flota superior a los 12 millones de embarcaciones de recreo, de acuerdo a Boating Industry (2011). Se estima que entre las costas del sur de Estados Unidos y Cuba navegan más de un millón de yates, según Gómez González (2015). El propio autor afirma que Cuba, en un escenario distendido en las relaciones con Estados Unidos, se convertirá en el principal destino náutico del Caribe. De acuerdo a Díaz Escrich (2015) una vez que se levanten las restricciones de viajes impuestas por el gobierno de los Estados Unidos un aproximado de 60000 yates estadounidenses atracarán en puerto cubano. En este escenario se ha incrementado progresivamente el arribo de yatistas a distintas marinas del país y Holguín posee la Marina Internacional de Vita, con facilidades para el atraque de yates, además de atractivos de interés para este segmento. Por otra parte, se realizan operaciones de cruceros estadounidenses en los puertos de La Habana, Cienfuegos y Santiago de Cuba. Holguín, por su posición geográfica, sus potencialidades en relación con la oferta turística actual y perspectiva y las operaciones de cruceros europeos realizadas por el puerto de Antilla, tiene posibilidades de incluirse en los circuitos de cruceros estadounidenses.

Desde la propia actualización del modelo de desarrollo económico cubano aprobada en el VI Congreso del PCC (2011) se definió como una meta para el sector turístico "incrementar los arribos, diversificando los mercados emisores y los segmentos de clientes, elevando los ritmos de crecimiento en correspondencia con el desarrollo turístico" (Lineamiento 259) y también "crear, diversificar y consolidar de forma 
acelerada servicios y ofertas complementarias al alojamiento que distingan al país, priorizando el desarrollo de las modalidades: ... marinas y náutica..." (Lineamiento 260). Esta política fue ratificada en el VII Congreso del PCC, desarrollado en 2016, donde se plantea en el lineamiento 207 de la Política Económica y Social "la actividad turística deberá tener un crecimiento acelerado que garantice la sostenibilidad y dinamice la economía, incrementando de manera sostenida los ingresos y las utilidades, diversificando los mercados emisores y segmentos de clientes, y maximizando el ingreso medio por turista".

A pesar de las restricciones legales que en la actualidad desestimulan los flujos turísticos de estadounidenses a Cuba, se consideró conveniente evaluar la atractividad competitividad del destino turístico Holguín para segmentos de clientes estadounidense con el propósito de favorecer la elección o ampliación de los negocios turísticos con mayores posibilidades de éxito en este destino, una vez que se flexibilicen las restricciones a los estadounidenses para viajar a Cuba.

El análisis de la atractividad de destinos turísticos es fundamental, dado que permite contar con una herramienta esencial para la elección de negocios turísticos que se consideren más atractivos y para los que se tengan mejores condiciones para competir, además permite dar solución a un problema fundamental en la inadecuada forma de gestión de los negocios turísticos: el modo erróneo de penetrar en la competencia turística, según plantea Magallanes (2004).

\section{Desarrollo}

De acuerdo a Coeuré \& Rabaud (2003) "atractividad es la capacidad de un territorio para atraer y retener las empresas", por otra parte, Enright y Newton (2004) subrayaron que un destino es competitivo si puede atraer y satisfacer a turistas potenciales y que esta competitividad se determina tanto por los factores específicos del turismo, como por un abanico más amplio de factores que influyen a los proveedores del servicio turístico. Ritchie y Crouch (2003), entre los autores más citados en esta temática, plantean que lo que hace a un destino turístico verdaderamente competitivo es su habilidad para incrementar el gasto del turista y para atraer cada vez más visitantes, al tiempo que se les proporcionan experiencias memorables y satisfactorias, haciéndolo de manera rentable, incrementando el bienestar de los residentes y conservando los recursos del destino para las generaciones futuras.

Existen distintos métodos para medir la competitividad, entre ellos se destacan: Modelo de las fuerzas competitivas de Porter (1984), Modelo de Calgary de Crouch y Ritchie (2003), Modelo integrado de Dwyer y Kim (2003). Este último es la obra más importante en el análisis de la competitividad en el turismo, según Hong (2009). Los modelos anteriormente referidos, basan su funcionamiento en medir únicamente la competitividad en sus diferentes modalidades y excluyen el análisis de atractividad en ellos. Por otra parte, muchos de los factores identificados como cruciales de la competitividad no se pueden aplicar por la falta de indicadores disponibles y no comparables entre los diferentes destinos, por lo que a todos se les señala la gran complejidad que poseen a partir de la excesiva cantidad de indicadores y las dificultades y altos costos para obtener la información. Por estas razones fue necesario proponer un procedimiento más sencillo y ajustado a los intereses de la presente investigación, que partió de las experiencias 
precedentes y que favorece la obtención de la información necesaria sobre las variables a considerar para el estudio, por los propios investigadores. A continuación, se grafica y detalla el mismo, de forma resumida.

Figura 2. Procedimiento para diagnosticar la atractividad competitividad de un destino turístico para un mercado

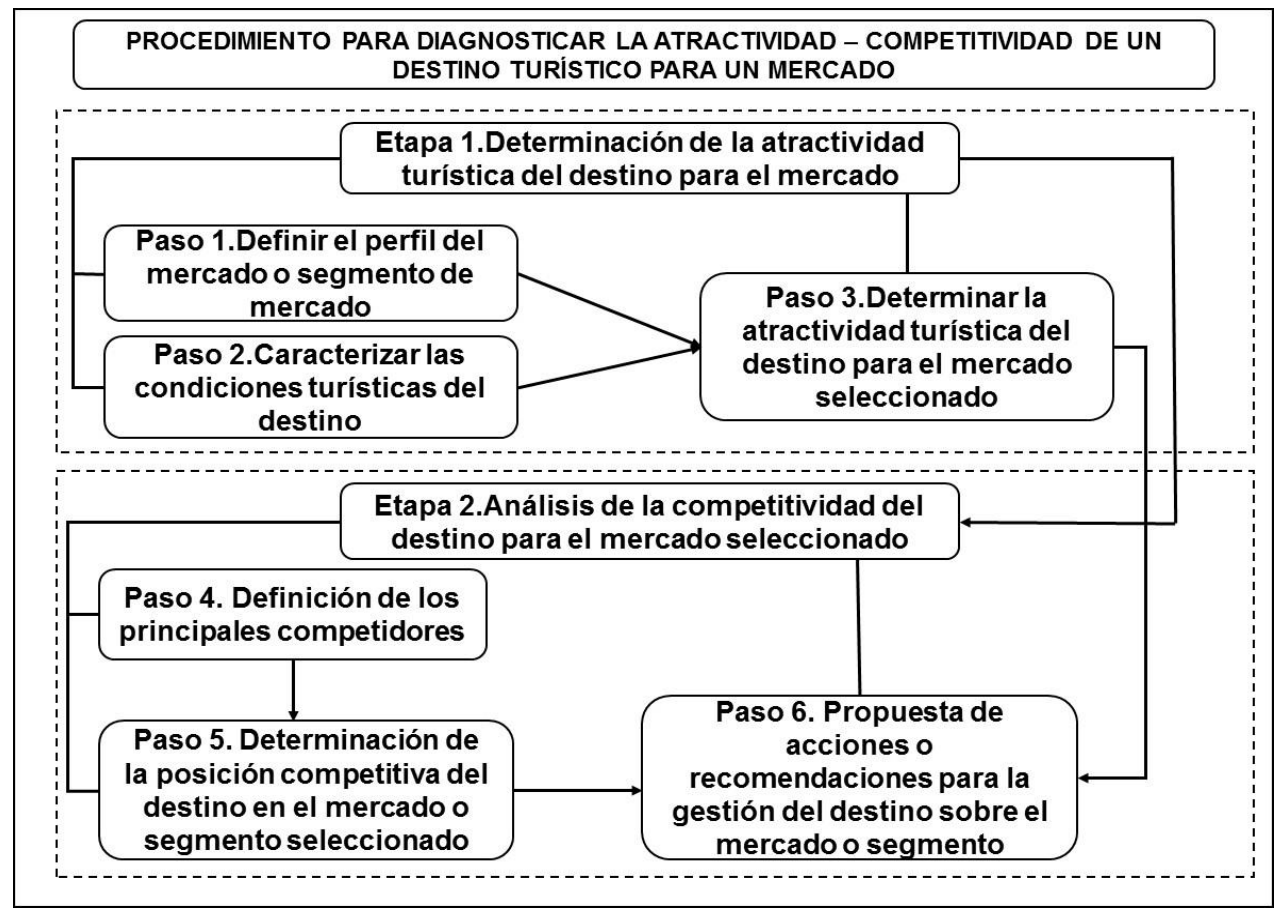

Procedimiento para diagnosticar la atractividad competitividad de un destino turístico para un mercado Figura 2.

Objetivo: Determinar la atractividad-competitividad turística de un destino para un mercado o segmento de mercado.

Etapa 1: Determinación de la atractividad turística del destino para el mercado o segmento seleccionado

Objetivo: Evaluar la correspondencia existente entre las condiciones turísticas del destino y las preferencias y características del mercado, precisando los aspectos favorables y desfavorables.

Paso1: Definir el perfil del mercado o segmento de mercado

Descripción: A partir de un conjunto de variables determinadas se debe conformar el perfil del mercado o segmento en estudio con la mayor amplitud y detalle posible.

Técnicas a emplear: Búsqueda de información secundaria en documentos de organizaciones territoriales, nacionales, internacionales y otras publicaciones; así como entrevistas.

Paso 2: Caracterizar las condiciones turísticas del destino

Descripción: Para caracterizar las condiciones del destino para el desarrollo de un mercado o segmento se proponen un conjunto de variables a caracterizar, a partir de las 
dimensiones y variables de atractividad definidas por Mas, Lozano, et. al. (2014) y los componentes del producto turístico total del destino propuestos por Serra (2003).

Técnicas a emplear:

- Entrevistas

- Revisión de informes de organizaciones turísticas del destino

- Búsqueda de información secundaria en Internet

Paso 3: Determinar la atractividad turística del destino para el mercado seleccionado

Descripción: Se deben identificar los Factores Clave de Éxito (FCE), a partir de alinear los aspectos más importantes para los clientes, contemplados en la caracterización del mercado, con la visión del destino y compararlos con las condiciones turísticas del destino, definidas en el paso dos, determinando los aspectos favorables y desfavorables en relación con la atractividad.

Técnicas a emplear:

- Estudio de caso para determinar los FCE

- Generación de ideas y técnicas de consenso para determinar los aspectos favorables y desfavorables

Etapa 2: Análisis de la competitividad del destino para el mercado seleccionado

Objetivo: Determinar la posición que ocupa el destino en relación con los competidores para el mercado o segmento seleccionado y proponer acciones o recomendaciones para la gestión del destino sobre el mercado o segmento seleccionado.

Paso 4: Definición de los principales competidores

Descripción: Se deben definir los principales competidores de la organización en el área geográfica determinada, teniendo en cuenta los que mayor importancia o cuota de mercado.

Técnicas a emplear:

- Estudio de caso

- Búsqueda de información secundaria en Internet

Paso 5: Determinar la posición competitiva del destino en el mercado o segmento seleccionado

Descripción: Se deben evaluar los resultados de la gestión del destino en dicho mercado o segmento y su comparación con los resultados de los competidores, también en relación con el mercado o segmento seleccionado y determinar la posición competitiva del destino respecto a los competidores, considerando un grupo de 13 indicadores que fueron definidos a partir del estudio de los indicadores más empleados por los autores que abordan este tema, buscando utilizar los más valiosos para realizar el análisis y a la vez que sea factible la obtención y comparación de la información. 
Como quiera que se consideran indicadores cuantitativos y cualitativos, se requiere homogeneizar los datos obtenidos, para lo cual se debe utilizar la fórmula de estandarización propuesta por Sarmiento Ramírez (2014).

$$
Z_{i}=\frac{X_{i}-X_{i} \operatorname{mín}}{X_{i} m a ́ x-X_{i} m i ́ n}
$$

donde:

- Zi: Valor estandarizado

- Xi: valor de la variable

- Xi mín: mínimo valor de las variables

- Xi máx: máximo valor de las variables

Luego se integran los datos en un índice, para lo cual se propone el método del promedio simple, donde se suman los factores y se dividen entre el número total de factores analizados. Este método simplifica la complejidad del cálculo y permite el objetivo que se persigue, la integración de los factores en un índice, que permite determinar la posición competitiva de los destinos evaluados.

Técnicas a emplear

- Análisis documental

- Búsqueda de información secundaria en Internet

- Entrevistas

- Criterio de especialistas

- Trabajo en grupos

- Procesador de datos Microsoft Office Excell

- Estadística descriptiva

Paso 6: Propuesta de acciones o recomendaciones para la gestión del destino sobre el mercado o segmento

Descripción: Se deben proponer acciones o recomendaciones para la gestión del destino sobre el mercado o segmento seleccionado, a partir de los elementos de atractividad desfavorables definidos en el paso 3 , de la posición competitiva que ocupa el destino determinada en el paso $5 \mathrm{y}$ de la experiencia obtenida por el investigador durante el desarrollo del estudio, que sirvan de guía u orientación para la toma de decisiones.

Técnicas a emplear

- Estudio de caso

- Generación de ideas

La aplicación de este procedimiento para el destino turístico Holguín dirigido a los segmentos de clientes estadounidenses que arriban por vía marítima (yatistas y cruceristas) y aérea permitió obtener como principales resultados los siguientes.

Determinación de la atractividad - competitividad turística del destino holguín para el segmento de yatistas estadounidenses. 
Para realizar este análisis se identificaron los aspectos más importantes para los yatistas estadounidenses, que se alinean con la visión del destino; los que se definieron como Factores Clave de Éxito (FCE) y luego se compararon, a través de estudio de casos, con las condiciones turísticas de Holguín, lo que permitió determinar los aspectos favorables y también los aspectos desfavorables de Holguín para los yatistas estadounidenses, los que se detallan a continuación.

Aspectos favorables

1. Existencia de numerosos atractivos culturales y naturales de interés para el segmento de mercado

2. La Marina Internacional de Vita posee servicios básicos para el yatista que favorecen la estancia de los mismos en sus instalaciones

3. El destino Holguín cuenta con amplios programas de actividades para satisfacer las necesidades de las parejas, familias, grupos de amigos y otras que permiten satisfacer los diferentes grupos de yatistas

4. El destino cuenta con una oferta culinaria autóctona, especialmente en Gibara, además la Marina Internacional de Vita incluye la restauración como un servicio complementario al yatista

5. Presencia de alojamiento estatal y no estatal con las características y estándares de calidad requeridos para satisfacer el segmento de yatistas estadounidenses

6. La práctica adecuada del idioma inglés por parte de los trabajadores del sector turístico y de la población en general

7. En el destino se ofrecen diversas actividades náuticas, como la pesca, buceo contemplativo, paseos en catamarán, etc., además de los servicios en los puntos náuticos.

Aspectos desfavorables

1. Insuficiente presencia de información sobre las facilidades de la Marina Internacional de Vita y del destino Holguín en Internet y redes sociales

2. Insuficiencias de la red de venta y otros servicios en la marina Puerto de Vita para asegurar todo el aprovisionamiento requerido por los yatistas

3. El destino aún no se incluye dentro de las operaciones de ningún turoperador que trabaje el segmento de yatistas estadounidenses en Cuba

4. Aplicación en Cuba del gravamen del 10 por ciento del cambio de moneda del dólar estadounidense al peso convertible cubano.

Para determinar la posición competitiva del destino turístico Holguín para el segmento de yatistas estadounidenses se debe considerar que Holguín es un mercado potencial para los yatistas procedentes de Estados Unidos, por lo que los indicadores cuantitativos incluidos en el procedimiento no se consideran en el análisis, ya que no serían comparables con los destinos que si operan ya con dicho segmento. El análisis se realizó con siete de las variables propuestas en el procedimiento, caracterizando cada una en los diferentes destinos. Como quiera que las variables utilizadas son cualitativas se le otorgó a cada una un valor cuantitativo, a partir de la caracterización realizada, utilizando una escala donde 5 equivale a muy favorable, 4 a favorable, 3 a medianamente favorable, 2 desfavorable y 1 equivale a muy desfavorable. Para otorgar la calificación anterior a las variables por destino se utilizó el criterio de especialistas. Luego se estandarizaron los resultados y se 
calculó un índice de competitividad para cada destino que integra la evaluación de las variables consideradas. El resultado obtenido se muestra a continuación en la tabla No. 2.

Tabla No.1: Cálculo del índice de competitividad por destino para el segmento de yatistas

\begin{tabular}{|l|c|c|c|c|}
\hline \multicolumn{1}{|c|}{ Indicadores/destinos } & Holguín & Cienfuegos & Matanzas & $\begin{array}{c}\text { La } \\
\text { Habana }\end{array}$ \\
\hline Recursos turísticos & 0,5 & 0 & 1 & 1 \\
\hline $\begin{array}{l}\text { Reconocimiento de preparación } \\
\text { y profesionalidad de RRHH }\end{array}$ & 1 & 0 & 0 & 0 \\
\hline Seguridad y tranquilidad & 0 & 0 & 0 & 0 \\
\hline Gestión medioambiental & 0 & 1 & 0 & 0 \\
\hline Aceptación residentes & 0 & 0 & 0 & 0 \\
\hline Infraestructura de servicio & 0 & 0,2 & 1 & 0,6666 \\
\hline Facilidad de transporte interno & 0 & 0 & 0 & 0 \\
\hline Índice de competitividad & 0,2143 & 0,1714 & 0,2857 & 0,2381 \\
\hline
\end{tabular}

Se obtuvo como resultado que el destino turístico Holguín ocupa el tercer puesto dentro de los destinos analizados, ubicándose por encima de Cienfuegos y por debajo de Matanzas y La Habana, en relación a los indicadores evaluados, con incidencia negativa para Vita de la variable infraestructura de servicio y resaltando positivamente el reconocimiento de los clientes sobre la preparación y profesionalidad de los recursos humanos. Para atenuar los aspectos negativos y mejorar la posición competitiva del destino Holguín para este segmento se propusieron un grupo de acciones o recomendaciones que se detallan seguidamente.

1. Incrementar la comunicación promocional de la Marina Internacional de Vita a través de los sitios de los turoperadores que trabajan este segmento

2. Ampliar la información sobre las facilidades de la Marina Internacional de Vita y los atractivos del destino Holguín a través de las redes sociales, principalmente: activecaptain, Facebook y el sitio tripadvisor

3. Realizar acciones de relaciones públicas online con clubes de yatistas estadounidense

4. Ampliar la infraestructura de servicios en la Marina Internacional de Vita que incluya: Tiendas, diversos restaurantes, facilidades de acceso a Internet, reserva de excursiones, entre otros servicios; así como completar la infraestructura de apoyo para satisfacer todas las necesidades de aprovisionamiento del yatista.

Determinación de la atractividad turística del destino holguín para el segmento de cruceristas estadounidenses

Se siguieron los pasos previstos en el procedimiento y se determinaron los aspectos favorables y desfavorables del destino Holguín para este segmento, los que se detallan a continuación.

Favorables

1. Cercanía entre el país emisor y receptor 
2. Buen nivel de idioma por parte de los trabajadores del sector y de los residentes

3. Existencia de gran número de atractivos tanto naturales como culturales, que se encuentran entre las preferencias de los cruceristas, destacándose las ofertas culturales y recreativas de las ciudades de Antilla, Banes y Holguín, así como la presencia de otros atractivos importantes cercanos al puerto de Antilla

4. La población local posee un alto nivel de implicación con la actividad turística

5. Excelentes condiciones climáticas en el destino para el desarrollo de esta modalidad, por la escasa presencia de eventos naturales que la puedan interferir.

Entre los aspectos desfavorables se encuentran:

1. Poco acondicionamiento del área de atraque en el puerto de Antilla

2. Insuficiencia de la red de compras en el destino

3. Desventajas en las tasas de cambio entre el dólar estadounidense y el CUC, al aplicársele un gravamen del 10 por ciento

4. Dificultades para acceder a las ofertas extra hoteleras por Internet desde cualquier punto y tampoco desde los teléfonos inteligentes.

Seguidamente se calculó el índice de competitividad considerando los destinos cubanos de cruceros en la actualidad. Los datos se muestran en la tabla siguiente:

Tabla No. 2: Cálculo del índice de competitividad por destino para el segmento de cruceristas

\begin{tabular}{|l|c|c|c|c|}
\hline & Holguín & $\begin{array}{c}\text { La } \\
\text { Habana }\end{array}$ & Cienfuegos & $\begin{array}{c}\text { Santiago de } \\
\text { Cuba }\end{array}$ \\
\hline Recursos turísticos disponibles & 0.5000 & 10.000 & 0.0000 & 10.000 \\
\hline $\begin{array}{l}\text { Preparación y profesionalidad del capital } \\
\text { humano }\end{array}$ & 0.0000 & 0.0000 & 0.0000 & 0.0000 \\
\hline Condiciones de seguridad y tranquilidad & 0.0000 & 0.0000 & 0.0000 & 0.0000 \\
\hline Infraestructura de servicio & 0.0000 & 10.000 & 0.6667 & 0.6667 \\
\hline Facilidades de transporte interno & 0.0000 & 0.0000 & 0.0000 & 0.0000 \\
\hline Gestión medio ambiental & 0.0000 & 0.0000 & 0.0000 & 0.0000 \\
\hline Aceptación por los residentes & 0.0000 & 0.0000 & 0.0000 & 0.0000 \\
\hline Índice de competitividad & 0.0714 & 0.2857 & 0.0952 & 0.2381 \\
\hline
\end{tabular}

Considerando que el destino Holguín se encuentra posicionado en el último lugar dentro de los competidores se han propuesto un conjunto de acciones con el objetivo de elevar la competitividad del destino, las que se resumen seguidamente.

1. Profundizar en los estudios de factibilidad sobre cuál debe ser el puerto de cruceros de Holguín, incluyendo en el análisis a Vita

2. Completar la infraestructura necesaria en el puerto de Antilla para la operación de cruceros (muelle con todas las condiciones, dragado, comunicaciones, información turística, facilidades para el cambio de moneda, etc.), en caso de que se mantenga como puerto para cruceros

3. Las Agencias de Viaje que atiendan la operación de cruceros estadounidenses deberán ofrecer una amplia variedad de excursiones a los cruceristas, fundamentalmente vinculadas a las ciudades, en correspondencia con los intereses de los clientes 
4. Recomendar a la dirección del destino y a las organizaciones transportistas de turismo, MITRANS y sector no estatal dar las facilidades y diferentes ofertas para satisfacer todas las necesidades de traslado interno de los cruceristas

5. Que las organizaciones implicadas estudien y ejecuten las soluciones necesarias para que los cruceristas realicen las compras en todos los lugares a visitar, incluyendo el puerto de atraque.

Determinación de la atractividad - competitividad turística del destino holguín para los clientes que acceden por vía aérea

La aplicación de los pasos previstos en el procedimiento para el segmento que accede al destino por vía aérea permitió determinar los aspectos favorables y desfavorables con que cuenta el destino Holguín para atraer flujos turísticos del mercado estadounidense. Los mismos se relacionan a continuación.

Aspectos favorables

1. Holguín posee atractivos histórico-culturales como monumentos, galería, museos, sitios patrimoniales, productos vinculados a la naturaleza y para la recreación diurna y nocturna; así como facilidades náuticas que permiten satisfacer sus principales motivos de viaje y desarrollar la mayoría de las actividades turísticas que prefieren

2. Existen en el destino hoteles con las características y estándares de calidad que prefieren los turistas estadounidenses, los cuales están preparados para atender clientes con un promedio de días de estancia igual o superior al de este mercado y ofrecen amplios programas de actividades para satisfacer las necesidades de los viajeros solitarios. Así mismo cuenta con casas de renta de buen estándar en varias ciudades y pueblos para los que prefieren este tipo de alojamiento

3. La preparación en idioma inglés de los trabajadores del sector del turismo en el destino Holguín es buena

4. Existe vinculación aérea directa entre el país emisor y el receptor, a través de numerosos vuelos regulares directos

Aspectos desfavorables

1. La red de tiendas y centros comerciales del destino Holguín es insuficiente para satisfacer una de sus actividades preferidas: las compras

2. Insuficiente facilidades para satisfacer las necesidades de búsqueda de información a través de los teléfonos inteligentes

3. El cambio de moneda se efectúa aplicando un gravamen del $10 \%$ lo que actúa en sentido contrario a la motivación de los clientes

El análisis realizado permitió concluir que en sentido general son más y de mayor peso los aspectos favorables que las insuficiencias, destacándose la capacidad del destino para satisfacer la mayoría de las preferencias de los turistas estadounidenses, en particular los atractivos con que cuenta y la posibilidad de solución en el corto y mediano plazo varios de los aspectos desfavorables, por lo que el destino Holguín es atractivo para los flujos turísticos de este mercado. 
Luego se realizó la evaluación de la competitividad. El resultado obtenido para este segmento se muestra a continuación, en la tabla No. 1.

Tabla No. 3: Cálculo del índice de competitividad del segmento que accede por vía aérea

\begin{tabular}{|l|c|c|c|c|}
\hline \multicolumn{1}{|c|}{ Indicadores/destinos } & Holguín & $\begin{array}{c}\text { La } \\
\text { Habana }\end{array}$ & Cancún & $\begin{array}{c}\text { Montego } \\
\text { Bay }\end{array}$ \\
\hline Recursos turísticos disponibles & 0 & 1 & 1 & 0 \\
\hline $\begin{array}{l}\text { Nivel de utilización de la tecnología para la } \\
\text { información y las comunicaciones en la } \\
\text { promoción y distribución de servicios y ofertas }\end{array}$ & 0 & 0 & 1 & 1 \\
\hline $\begin{array}{l}\text { Reconocimiento por los clientes de preparación } \\
\text { y profesionalidad de RRHH }\end{array}$ & 1 & 1 & 0 & 0 \\
\hline Condiciones de seguridad y tranquilidad & 1 & 1 & 0 & 0 \\
\hline Gestión medio ambiental & 1 & 1 & 0 & 0 \\
\hline Disponibilidad de la infraestructura necesaria & 0 & 0 & 1 & 1 \\
\hline Facilidades de transporte dentro del destino & 0 & 0 & 1 & 1 \\
\hline Promedio simple (Índice de competitividad) & 0.4285 & 0.5714 & 0.5714 & 0.4285 \\
\hline
\end{tabular}

Se obtuvo como resultado que el destino turístico Holguín se encuentra al mismo nivel de Montego Bay y por debajo de La Habana y Cancún, en relación a los indicadores evaluados. Los aspectos que más inciden negativamente en este resultado son el nivel de utilización de la tecnología y las facilidades de transporte dentro del destino.

Para mejorar la posición competitiva de Holguín se propusieron un conjunto de acciones o recomendaciones para la gestión del destino sobre este segmento, que se detallan a continuación.

1. Ampliar la disponibilidad de autos para la renta y el transporte turístico público en el destino

2. Aprovechar las tecnologías de la información y las comunicaciones disponibles en función de la promoción y comercialización del destino

3. Crear condiciones tecnológicas para satisfacer la demanda de información y reserva de los clientes desde sus teléfonos inteligentes

4. Ampliar la red de tiendas y centros comerciales del destino, así como la variedad de sus surtidos

Gestionar mayor especialización, variedad y calidad de las ofertas gastronómicas hoteleras y extra hoteleras de las organizaciones estatales, en particular

\section{Conclusiones}

La complejidad de los modelos para medir la competitividad de destinos turísticos consultados y la no integración en ellos de variables que consideren también la atractividad, implicaron la necesidad de proponer un procedimiento más sencillo y ajustado a los intereses de la presente investigación, que solucionara además la inclusión del análisis de la atractividad en el mismo y favoreciera la obtención de la información por parte de los propios investigadores 
$>$ Se determinó que el destino turístico Holguín es atractivo para los segmentos de clientes estadounidenses que arriban por vía aérea y marítima (yatistas y cruceristas), resaltando como aspectos más importantes y comunes para los tres segmentos los siguientes:

- La diversidad de atractivos culturales y naturales que posee

- Disponibilidad en el destino de alojamiento estatal y no estatal adecuado para satisfacer los intereses de los estadounidenses

- Cercanía entre el país emisor y receptor

- Existencia de acceso aéreo directo y facilidades para el acceso marítimo

- Buen nivel de idioma por parte de los trabajadores del sector y de los residentes, lo que favorece el intercambio

- La población local posee un nivel alto de implicación con la actividad turística.

Se determinaron como desventajas más importantes, en cuanto a la atractividad, las siguientes:

- La red de tiendas y centros comerciales del destino Holguín es insuficiente

- Aplicación en Cuba del gravamen del 10 por ciento del cambio de moneda del dólar estadounidense al peso convertible cubano

- Insuficiente comunicación promocional de los atractivos y facilidades del destino Holguín y pocas facilidades para satisfacer las necesidades de búsqueda de información y reserva a través de Internet y los teléfonos inteligentes

- Necesidad de completar la infraestructura marítima, en especial para el atraque de cruceros

Se determinó la posición competitiva del destino turístico Holguín respecto a los competidores en cada uno de los segmentos, precisándose que en general la posición es desventajosa, pero con potencialidades para mejorar los resultados en el corto y mediano plazo.

\section{Referencias Bibliográficas}

Díaz Escrich, J. M (2015). Aseguran que más de 60 mil yates estadounidenses podrían visitar Cuba anualmente. Publicación electrónica Cubadebate

Boating Industry (2011). Market Data Book 2011: The definitive guide to marine business statistics

Coeuré, B. \& Rabaud, I. (2003). “Attractivité de la France: analyse, perception et mesure. Économie et Statistiques"

Dwyer, L. y Kim, CH. (2003). Destination Competitiveness: Determinants and indicators 
Enright. J. M \& Newton, J. (2004) “Tourism destination competitiveness: a quantitative approach". Tourism Management (25)

Gómez González, A. (2015). Hello Cuba. Recuperado de http://oncubamagazine.com/economia-negocios/hello-cuba/. Consultado en abril de 2016

Hong, H. \& Kacperczyk, M. (2009). "The Price of sin: The effects of social norms on markets". EL SEVIER. Recuperado de http://pages.stern.nyu.edu/sternfin/mkacperc/public-html/sin.pdf. Consultado en mayo de 2016

Magallanes, A.J. (2004). "Atractividad de mercados turísticos". Internacional Thomson Editores. México

Mas, M., Losano, P., Trifaró, N., Owen, M., Fernández, M.V., Ramírez, G.,Krebs, A. (2014). Construcción de un indicador sintético de atractividad (SIET) de un destino turístico. VI Congreso Latinoamericano de Investigación Turística. Neuquén

OMT (2015). Panorama OMT 2015

ONEI (2017). Anuario Estadístico de Cuba. Disponible en www.onei.cu

PCC (2011). Lineamientos de la Política Económica y Social del Partido y la Revolución Cubana

PCC (2016). Actualización de los Lineamientos de la Política Económica y Social del Partido y la Revolución para el período 2016 - 2021

Porter, M. (1984). “Estrategia competitiva”. CECSA, México

Ritchie, J.R.B. y Crouch, G.I. (2003). The Competitive Destination. A Sustainable perspective. Tourism Management. (21)

Sarmiento Ramírez, Y. (2014). "Evaluación de la competitividad territorial para el proceso de planificación". Tesis en opción al grado científico de Doctor en Ciencias Económicas. Universidad de Camagüey. Facultad de Ciencias Económicas y Empresariales. Centro de estudios de Dirección empresarial y territorial. Camagüey, Cuba

Serra Cantallops, A. (2003). “Marketing turístico". Madrid, España. ESIC Editoriall

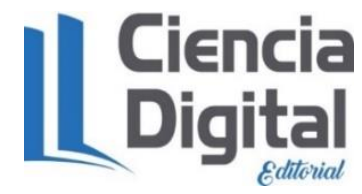




\section{Para citar el artículo indexado.}

Medina J., Pérez E. \& Riquenes M. (2018). Determinación de la competitividad de destino turístico. Aplicación en Holguín para el mercado Estadounidense. Revista electrónica Explorador Digital 2(3), 36-50. Recuperado desde:

http://cienciadigital.org/revistacienciadigital2/index.php/exploradordigital/article/view/335/7 $\underline{47}$

\section{LCiencia}

El artículo que se publica es de exclusiva responsabilidad de los autores y no necesariamente reflejan el pensamiento de la Revista Explorador Digital.

El articulo queda en propiedad de la revista y, por tanto, su publicación parcial y/o total en otro medio tiene que ser autorizado por el director o editor de la Revista Explorador Digital.
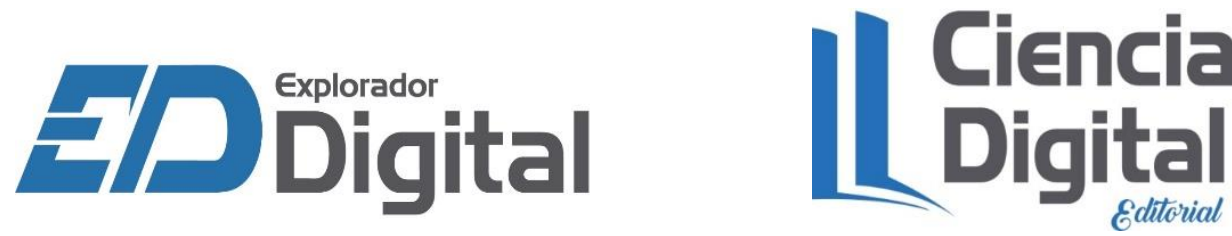